\title{
MODELLING OF THE SEPARATION PROCESS OF THE POTATO STACK
}

Taras Hutsol*, Jurii Firman, Sergiy Komarnitsky

Faculty of Engineering and Technology, State Agrarian and Engineering University in Podilya

${ }^{*}$ Corresponding author: e-mail: Pro-gp@pdatu.edu.ua

\begin{tabular}{|c|c|}
\hline ARTICLE INFO & ABSTRACT \\
\hline $\begin{array}{l}\text { Article history: } \\
\text { Received: August } 2017 \\
\text { Received in the revised form: } \\
\text { September } 2017 \\
\text { Accepted: September } 2017\end{array}$ & \multirow{2}{*}{$\begin{array}{l}\text { The most time consuming and the least mechanized process of potato } \\
\text { cultivation is its harvesting. Therefore, now, as never before, we have } \\
\text { faced a problem concerning the improvement of the existing and } \\
\text { construction of new devices for potato harvesting and their provision } \\
\text { to the cultivation industry. It requires further development of theoreti- } \\
\text { cal, complex and extensive research on the phenomenon of separation } \\
\text { of the potato stack, which will enable justification of optimal work } \\
\text { modes of the existing separating devices and will be used for the } \\
\text { synthesis of basically new, more advanced separators }\end{array}$} \\
\hline $\begin{array}{l}\text { Key words: } \\
\text { potato stack, } \\
\text { segregation, } \\
\text { sowing, } \\
\text { separation, }\end{array}$ & \\
\hline
\end{tabular}

\section{Введение}

Исследования ученых в изучении процесса сепарации проводились в следующих направлениях.

Кленин (1990), впервые изучив закономерности сепарации картофельного вороха по длине элеватора, предложил для описания явления просеивания почвы степенную функцию следующего вида:

$$
\varepsilon=1-Q_{0}^{-\left(\alpha_{1} x+1\right)}
$$

где:

$\varepsilon \quad$ - степень сепарации почвы

$Q_{0} \quad$ - масса почвы, которая поступила на элеватор

$x$ - длина элеватора

$\alpha_{1}-$ коэффициент, который зависит от типа и состояния почвы

Как видим, состояние картофельного вороха характеризуется только одним обобщенным показателем, который, безусловно, не может адекватно описать физическую модель почвы. Именно поэтому уравнение (1) не всегда соответствует реальному процессу сепарации почв различных типов. 
Более основательно процесс сепарации сыпучих материалов изучал Непомнящий (1962). Он подошел к исследованию явления сепарации исходя из положений теории вероятностей. Для описания процесса сепарации им предложено уравнение следующего вида:

$$
\varepsilon=1-\Phi\left(\frac{h}{2 B t}\right)\left[1-e^{-t / \tau_{0}}\right]
$$

где:

$$
\begin{array}{lll}
h & - & \text { начальная толщина слоя материала } \\
B & -\quad \text { стохастический коэффициент, который зависит от размеров частиц и } \\
& \text { свойств среды } \\
\tau_{0} & -\quad \text { постоянная времени процесса. }
\end{array}
$$

Результаты исследований указывают на то, что качество сепарации сыпучего материала зависит от времени сепарации, скорости перемещения материала и толщины слоя вороха на сепарирующей поверхности. Но уравнение (2) не учитывает специфических особенностей просеивания почвы и поэтому не может быть использовано для практических расчетов.

В теоретических исследованиях Непомнящего не учитывается также саморазрушение комков почвы в процессе сепарации. Этот фактор частично учтен в исследованиях Г.Д. Петрова (1984), который предложил уравнение следующего вида:

$$
\varepsilon=1-\mathrm{e}^{-k_{2} T}+(1-v) \frac{k_{2}}{k_{2}-k_{1}}\left(\mathrm{e}^{-k_{2} T}-\mathrm{e}^{-k_{1} T}\right)
$$

где:

$$
\begin{array}{cc}
k_{1} \text { и } k_{2}- & \begin{array}{l}
\text { коэффициенты, которые определяют способность комков к разрушению и } \\
\text { способность почвы к просеиванию соответственно }
\end{array} \\
v \quad-\quad \text { относительное содержание проходимой фракции в ворохе, поступающем } \\
\quad \text { на элеватор } \\
T \quad-\quad \text { время сепарации }
\end{array}
$$

Но уравнение (3) не соответствует реальному прохождению сепарации картофельного вороха. Анализируя это уравнение нетрудно заметить, что даже когда на сепараторе толщина вороха будет достаточно малой, то есть он будет размещаться в один слой, в ворохе еще будет значительное количество проходимой фракции. А экспериментальные исследования свидетельствуют о том, что уже в течение нескольких первых секунд на сепараторе остаются только частицы почвы непроходимой фракции.

Все остальные работы, посвященные исследованию процесса работы самых сепараторов, сводятся к изучению влияния сепарирующих рабочих органов на отдельно взятые частицы вороха.

Итак, до сих пор не было проведено обстоятельного изучения явления сепарации картофельного вороха. 
Modelling of the separation...

Целью статьи является выявление природы сепарации картофельного вороха и факторов, влияющих на показатели процесса сепарации, а также выявление оптимальных методов моделирования этого процесса.

Процесс сепарации картофельного вороха можно условно представить как три взаимосвязанных процесса:

Разрушение комков. В подавляющем большинстве работ по разрушению комков почвы, этот процесс рассматривается как протекающий с одинаковой интенсивностью по всему объему вороха. На самом деле разрушение комков происходит интенсивнее по мере приближения к поверхности сепарирующего органа и менее интенсивно с удалением от него. Этот вопрос приобретает решающее значение при рассмотрении работы активных сепараторов.

Итак, чрезвычайно важным является вопрос изучения изменения фракционного состава вороха по толщине, то есть его изменение под влиянием разрушения комков и перемешивания.

Перемешивание вороха. Как показывают результаты экспериментальных исследований, интенсивность перемешивания почвы играет решающую роль в качестве сепарации вороха, особенно на начальном этапе сепарации, когда толщина слоя вороха достаточно значительна.

В результате перемешивания вороха возникает явление сегрегации, которое заключается в том, что мелкие частицы вороха опускаются вниз, а крупные частицы поднимаются на поверхность. Благодаря сегрегации мелкие части почвы быстро достигают рабочей поверхности сепаратора и просеиваются. Итак, фракционный состав вороха по толщине непрерывно меняется.

Просеивание мелких частей вороха, которые оказались на поверхности cenapamopa. Влияние этого фактора на процесс сепарации является наиболее изученным. Исследования ученых сводятся к тому, что интенсивность просеивания почвы пропорциональна количеству вороха проходимой фракции на поверхности сепаратора.

Существует много реальных физических явлений, которые в настоящее время не могут быть теоретически обоснованы. Примером такого явления является сепарация картофельного вороха сепараторами картофелеуборочных машин. Однако это явление, как и многие другие, можно исследовать с помощью имитационного моделирования. Существенным преимуществом моделирования является то, что различные физические эффекты, которые наблюдаются в реальном явлении, могут рассматриваться изолированно, что позволяет лучше понять сам характер протекания процесса. Так, довольно сложно рассматривать и моделировать реальные материалы, так как компоненты смеси имеют неодинаковый размер, форму, физикомеханические свойства и тому подобное. При моделировании упрощенных процессов можно включить или исключить тот или иной эффект или свойство и тем самым описать влияние каждого фактора на процесс.

Таким образом, моделирование процесса численными методами можно приравнять к теоретическому обоснованию явления. Такое моделирование позволяет понять физические свойства и процессы благодаря полному контролю условий «эксперимента» в «компьютерном эксперименте», а также дает возможность исследовать каждый аспект явления максимально детализировано. 
Поскольку явление сегрегации достаточно сложное и зависит от большого количества факторов, рассмотрим упрощенную математическую модель. При этом разделим массу вороха по размерам частиц на две фракции: проходимую $q_{n}$ частицы которой могут быть просеяны без предварительного разрушения, и непроходимую $q_{n}-$ размеры частиц которой больше размеров просветов сепарирующей поверхности.

Предположим также, что в момент попадания вороха на сепаратор масса однородная, то есть во всем объеме равномерно распределены частицы всех размерных фракций.

Пласт картофельного вороха, который находится на поверхности сепаратора, поделим на $M$ горизонтальных слоев. Тогда $i$-й слой будет составлять ворох, который будет находиться на расстоянии $h$ от поверхности сепаратора, т.е.

$$
\frac{(i-1)}{M} H<h \leq \frac{i}{M} H,
$$

где:

$H$ - толщина слоя вороха, поступающего на сепаратор

Очевидно, что в результате перемешивания вороха, встряхивания рабочей поверхности сепаратора и т.п. частицы массы будут осуществлять хаотическое движение. Однако средние значения скоростей движения частиц окажутся направленными. Так мелкие частицы вороха будут опускаться вниз, а крупные частицы будут подниматься на поверхность.

Попробуем обосновать процесс сегрегации почвы с учетом фракционного состава почвы. Рассмотрим баланс $i$-го слоя почвы (Рис. 1).

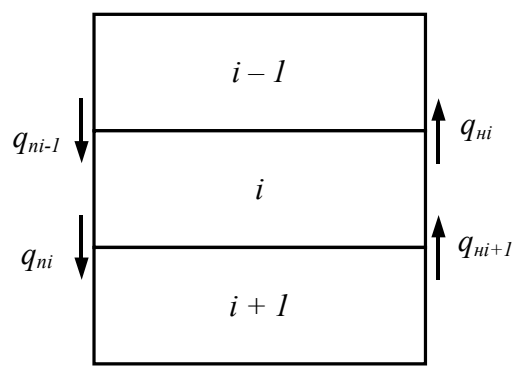

Рисунок 1. Баланс і-го слоя почвы

Тогда уравнение баланса для $i$-го слоя вороха записывается следующим образом:

$$
q_{n i}^{c}+q_{n i-1}^{c}-q_{H i}^{c}-q_{H i+1}^{c}=0
$$

А количество вороха определенной фракции в $i$-м слое в момент времени $\tau$ будет определяться уравнениями: 
Modelling of the separation...

$$
\begin{gathered}
q_{n i \tau}=q_{n i \tau-1}+q_{n i-1}^{c}-q_{n i}^{c} \\
q_{H i \tau}=q_{H i \tau-1}+q_{H i+1}^{c}-q_{H i}^{c}
\end{gathered}
$$

Приняв скорость сегрегации частиц определенной фракции с $i$-1-го слоя в $i$-й слой пропорционально количеству почвы этой фракции в $i-1$-м слое и количества почвы другой фракции в $i$-м слое вороха, после преобразований получим:

$$
\begin{aligned}
& q_{n i}^{\tau+1}=q_{n i}+k \cdot\left(q_{n i-1} \cdot\left(1-q_{n i}\right)-q_{n i} \cdot\left(1-q_{n i+1}\right)\right) \\
& q_{H i}^{\tau+1}=q_{H i}+k \cdot\left(q_{H i+1} \cdot\left(1-q_{H i}\right)-q_{H i} \cdot\left(1-q_{H i-1}\right)\right)
\end{aligned}
$$

Как видим, количество почвы определенной фракции в определенном слое картофельного вороха зависит от количества почвы этой же фракции в предыдущий момент времени в этом же слое, а также в слоях, которые находятся непосредственно сверху и снизу этого слоя картофельного вороха.

Данная имитационная модель отличается от существующих тем, что не требует очень высоких вычислительных мощностей и может быть реализована с помощью обычного математического процессора (Рис. 2).

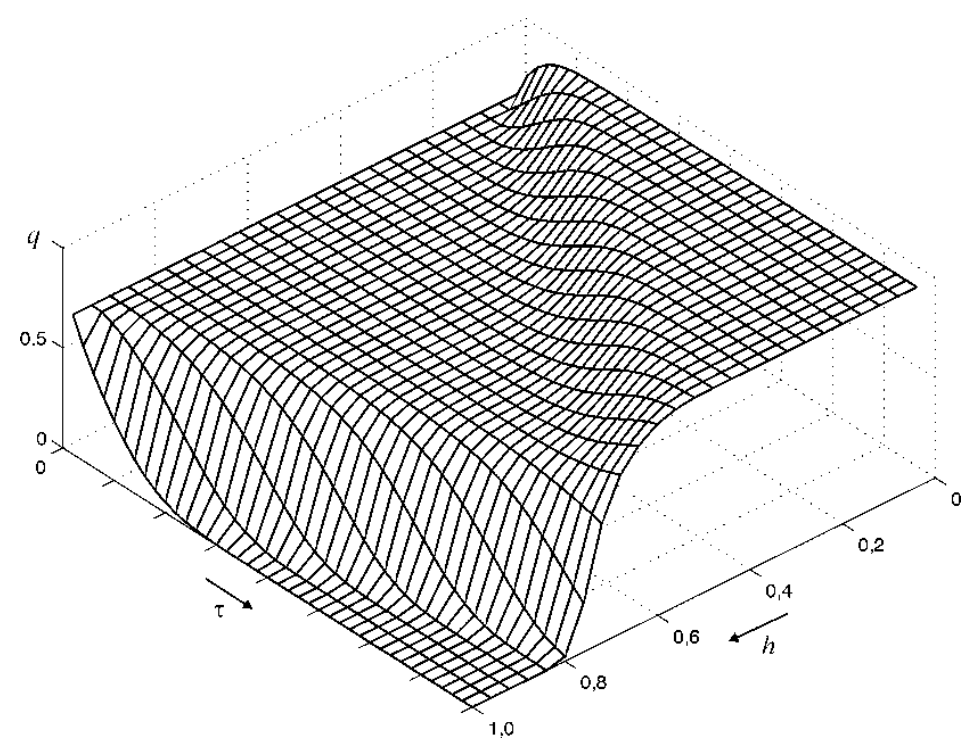

Рисунок 2. Динамика изменения фракиионного состава вороха по толщине пласта

Как видно с рисунка 2 с увеличением времени сегрегации частицы проходимой фракции опускаются до сепарирующей поверхности, а частицы непроходимой фракции поднимаются на поверхность, следовательно, модель является адекватной. 
Математическую модель, приведенную выше, можно дополнить с учетом разрушения комков. Тогда количество разрушенной почвы в $i$-м слое вороха запишется следующим образом:

$$
q_{i}^{3 p}=\varepsilon \cdot q_{H i}=q_{H i} \cdot e^{-r \cdot h}
$$

Уравнения (8) и (9) приобретают вид:

$$
q_{n i}^{\tau+1}=q_{n i}+k \cdot\left(q_{n i-1} \cdot\left(1-q_{n i}\right)-q_{n i} \cdot\left(1-q_{n i+1}\right)\right)+\left(1-q_{n i}\right) \cdot e^{-r \cdot h}
$$

или

$$
q_{H i}^{\tau+1}=q_{H i}+k \cdot\left(q_{H i+1} \cdot\left(1-q_{H i}\right)-q_{H i} \cdot\left(1-q_{H i-1}\right)\right)-q_{H i} \cdot e^{-r \cdot h}
$$

Для учета просеивания почвы активным рабочим органом можно принять, что часть проходной фракции, достигшей поверхности сепаратора $(h=0)$ просеивается.

Расчетная зависимость для имитационного моделирования количества просеянной почвы в определенный момент времени будет иметь вид:

$$
S^{\tau}=s \cdot q_{n M}^{\tau-1}
$$

где:

$$
\begin{array}{ll}
s & - \text { интенсивность сепарации почвы } \\
q_{n м} & - \text { количество почвы проходимой фракции в нижнем слое вороха }
\end{array}
$$

Результаты реализации имитационной модели сепарации почвы с учетом сегрегации и активного разрушения комков в математическом процессоре MATLAB 6 для 2-фракционного вороха приведены на рис. 3.

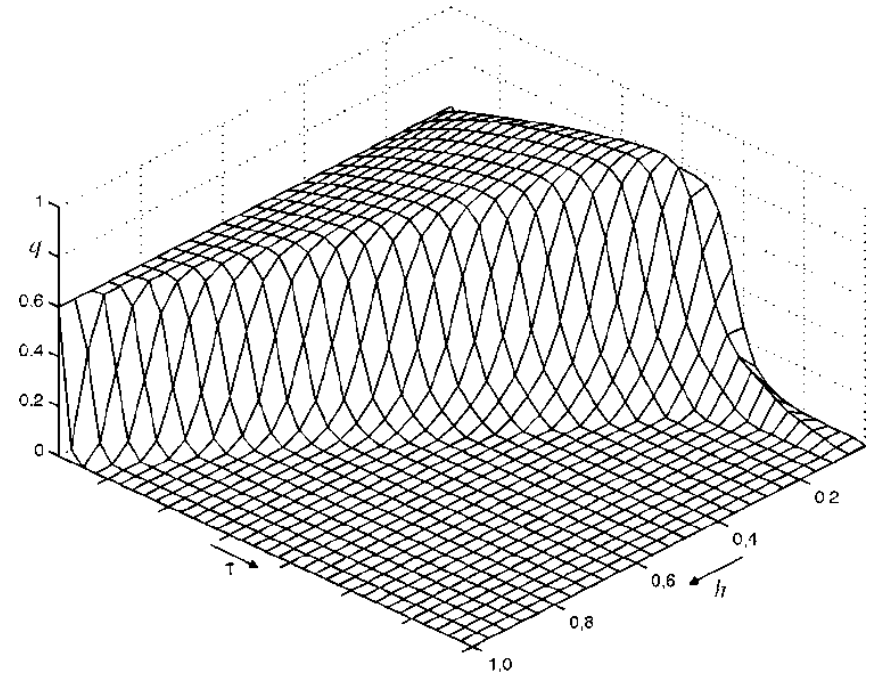

Рисунок 3. Динамика изменения количества почвы просевной фракции на сепараторе 
Modelling of the separation...

Как видно с рис. 3 со временем частицы вороха проходимой фракции опускаются на поверхность сепаратора и просеиваются, а на сепараторе остаются только частицы вороха непроходимой фракции.

Проведем анализ полученной числовой имитационной модели. Как сказано выше, основным параметром оптимизации для сепараторов картофелеуборочных машин является степень сепарации почвы, следовательно, обнаружим влияние основных факторов на показатель степени сепарации почвы.

Факторами, которые могут быть переменными в нашей числовой имитационной модели, являются:

- интенсивность сегрегации почвы (характеризует скорость сегрегации почвы, определяется свойствами картофельного вороха, а также интенсивностью перемешивания массы вороха);

- интенсивность разрушения комков (характеризует скорость разрушения комков, определяется свойствами комков почвы, а также интенсивностью действия сепаратора на ворох);

- начальный фракционный состав картофельного вороха (определяется механикотехнологическими свойствами картофельного вороха);

- толщина слоя вороха на сепараторе (определяется подачей вороха на сепаратор и скоростью движения сепарирующей поверхности);

- время сепарации (определяется скоростью движения сепарирующей поверхности, а также ее длиной).

Зависимость интенсивности сепарации от интенсивности сегрегации почвы приведена на рис. 4.

Итак, с увеличением сегрегации почвы увеличивается интенсивность сепарации картофельного вороха, а также сокращается время интенсивной сепарации. Это объясняется тем, что при высокой интенсивности сегрегации ускоряется просеивание проходимой фракции почвы, затем происходит резкий переход к просеиванию почвы, которая образуется при разрушении комков непроходимой фракции.

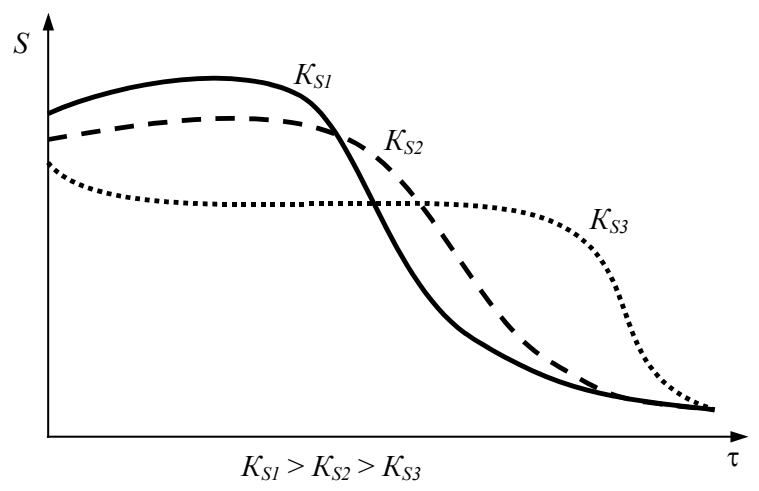

Рисунок 4. Зависимость интенсивности сепаращии от коэффищиента сегрегащии nочвbl 
На рис. 5 приведен график зависимости степени сепарации картофельного вороха от интенсивности сегрегации почвы.

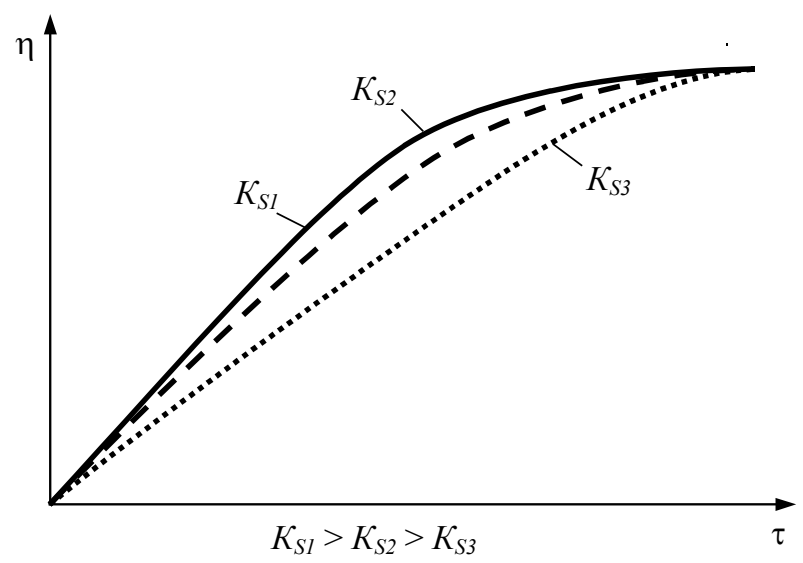

Рисунок 5. Зависимость степени сепарации картофельного вороха от коэффициента сегрегаџии почвы

C pис. 5 видно, что на начальном этапе зависимость степени сепарации картофельного вороха от коэффициента сегрегации почвы приближенный к линейному характеру, а со временем асимптотически приближается к зависимости с максимальным значением коэффициента сегрегации.

Зависимость интенсивности разрушения комков почвы от интенсивности сегрегации почвы приведена на рис. 6.

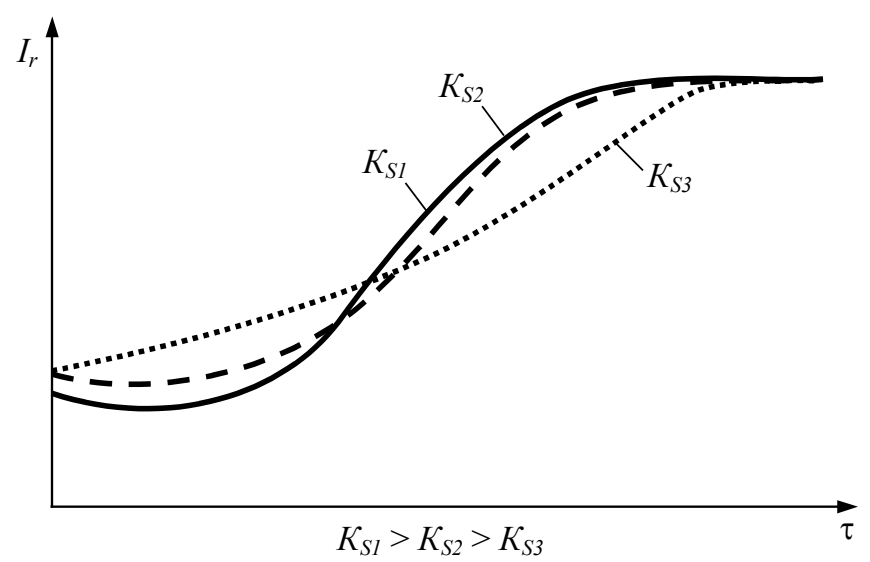

Рисунок 6. Зависимость интенсивности разрушения комков почвы от коэффициента сегрегачии почвы 
Modelling of the separation...

Таким образом, при малых значениях интенсивности сегрегации интенсивность разрушения комков почвы со временем плавно увеличивается. С увеличением интенсивности сегрегации разрушение комков сначала замедляется, а затем резко увеличивается, приближаясь к максимальному значению в момент, когда на сепараторе остаются только частицы вороха непроходимой фракции.

\section{Выводы}

1. Имитационное моделирование процесса сепарации картофельного вороха позволяет исследовать все аспекты процессов, которые происходят в слое вороха и на поверхности сепаратора, дает возможность исследовать каждый аспект максимально детализировано и обособленно от других.

2. Хотя приведенная имитационная модель является очень упрощенной, ее показатели достаточно близки к результатам экспериментальных исследований, а после экспериментального обоснования сути коэффициентов интенсивности сегрегации и интенсивности разрушения комков почвы модель можно использовать для практических расчетов сепараторов картофелеуборочных машин.

\section{Литература}

Бышов, Н. В. (2000). Научно-методические основы расчета сепарирующих рабочих органов и повышение эффективности картофелеуборочных машин. Автореферат диссертации на соискание научной степени доктора технических наук. Москва. РГСХА, 40.

Булгаков В.М., Гуцол Т.Д., Новак Я. (2012) Современное состояние производства картофеля u перспективы разработки картофелеуборочных машин. Сборник научных трудов Винницкого национального аграрного университета. Винница, pp. 103-109.

Завалишин, Ф. С. (1973). Основы расчета механизированных процессов в растениеводстве. Москва. Колос, 319.

Кленин, Н.И., Сакун, В.А. (1990). Сельскохозяйственные и мелиоративные машины. Москва Колос, 672 .

Непомнящий, Е.А. (1962). Некоторые результаты теоретического анализа процесса грохочения. Обогащение руд. 5. 29-35.

Петров, Г.Д. (1984). Картофелеуборочные машины. Москва. Машиностроение, 320.

\section{MODELOWANIE PROCESU SEPARACJI STERTY ZIEMNIAKA}

Streszczenie. Najbardziej czasochłonnym a jednocześnie najmniej zmechanizowanym procesem uprawy ziemniaków jest jego zbiór. Dlatego teraz, jak nigdy dotąd, powstaje problem z udoskonaleniem istniejących i stworzeniem nowych narzędzi do zbioru ziemniaków i ostatecznie dostarczeniem tych nowoczesnych, wydajnych i niezawodnych narzędzi do przemysłu uprawnego. Rozwiązanie tego problemu wymaga dalszego rozwoju badań teoretycznych, kompleksowego i obszernego badania zjawiska separacji sterty ziemniaka, co pozwoli na uzasadnienie optymalnych trybów pracy istniejących urządzeń separujących, a także na syntezę zasadniczo nowych, bardziej zaawansowanych separatorów.

Słowa kluczowe: sterty ziemniaka, segregacja, przesiewanie, separacja, modelowania 